Article

\title{
Polyphenol Characterization and Skin-Preserving Properties of Hydroalcoholic Flower Extract from Himantoglossum robertianum (Orchidaceae)
}

\author{
Miriam Bazzicalupo ${ }^{1}$, Bruno Burlando ${ }^{2,3}{ }^{\oplus}$, Marcella Denaro ${ }^{4}$, Davide Barreca ${ }^{4}(\mathbb{D}$, \\ Domenico Trombetta ${ }^{4}\left(\mathbb{D}\right.$, Antonella Smeriglio ${ }^{4}(\mathbb{D})$ and Laura Cornara ${ }^{1, *}$ \\ 1 Department of Earth, Environment and Life Sciences, University of Genova, 16132 Genova, Italy; \\ miriamb91@hotmail.it \\ 2 Department of Pharmacy, University of Genova, 16132 Genova, Italy; burlando@difar.unige.it \\ 3 Institute of Biophysics, National Research Council (CNR), 16149 Rome, Italy \\ 4 Department of Chemical, Biological, Pharmaceutical and Environmental Sciences, University of Messina, \\ 98168 Messina, Italy; mdenaro@unime.it (M.D.); dbarreca@unime.it (D.B.); dtrombetta@unime.it (D.T.); \\ asmeriglio@unime.it (A.S.) \\ * Correspondence: cornaral@gmail.com; Tel.: +39-010-209-9364
}

Received: 20 October 2019; Accepted: 12 November 2019; Published: 14 November 2019

check for updates

\begin{abstract}
Himantoglossum robertianum (Loisel.) P. Delforge is a Mediterranean orchid whose propagation in vitro has been achieved, making it eligible as a source of bioactive substances. Flowers were analyzed by light and SEM microscopy and used to obtain a polyphenol-rich, hydroalcoholic flower extract (HFE). HFE was characterized for total phenols, flavonoids and proanthocyanidins, and for polyphenol profile by RP-LC-DAD. Antioxidant assays, in vitro collagenase and elastase inhibition, and MTT and cell motility assays on $\mathrm{HaCaT}$ keratinocytes were done. Microscopy showed epidermal cells containing anthocyanins in the flower labellum. Flavonoids (flavones and flavan-3-ols) represented the most abundant compounds (42.91\%), followed by scopoletin (33.79\%), and phenolic acids (23.3\%). Antioxidant assays showed strong activities, rating ORAC $>$ FRAP $>$ TEAC $>\beta$-carotene bleaching $>$ DPPH $>$ iron-chelation. Biological assays showed elastase and collagenase inhibition (up to $42 \%$ and $78 \%$, respectively), improvement of $\mathrm{HaCaT}$ cell viability after treatment with $500 \mu \mathrm{M} \mathrm{H}_{2} \mathrm{O}_{2}$ (from $30 \%$ to $84 \%$ of control), and stimulation of cell migration rate up to $210 \%$ of control. In summary, HFE counteracted different free radicals, while protective properties were shown by cell-free and cell-based bioassays, suggesting the possible use of $H$. robertianum flowers for skin-preserving, repair, and anti-aging applications.
\end{abstract}

Keywords: antioxidants; collagenase; elastase; flavonoids; keratinocytes; skin aging; Himantoglossum robertianum

\section{Introduction}

Orchids have been widely used in the folk tradition to treat several ailments, including tuberculosis, inflammation, hepatitis, wounds and sores, tumor, asthma, malaria, and menstrual disorders [1]. The uses of Anacamptis morio L. and Epipactis helleborine (L.) Crantz for wound healing have been reported [2], while a number of species are known as sources of bioactive compounds [3-5].

Different studies have started to explore the biological activities of orchid extracts, especially with reference to skin care applications. A cosmetic serum containing $5 \%$ orchid extracts, including the Marcella Koss intergeneric hybrid of Brassocattleya, has been tested in vivo for its skin-whitening properties on melasma and lentigo senilis in Japanese women [6]. In a study about the potential of 
Vanda coerulea Griff. ex Lindl., and V. teres (Roxb.) Lindl. extracts as an anti-aging and skin-moisturizing agent, the importance of mucilage to maintain skin hydration has been highlighted [7].

Extracts from various portions of three hybrids of Phalaenopsis species, bearing white, yellow, and purple pigmentation, have been tested for their antioxidant power. This study has revealed that in each species, flower and leaf extracts have higher antioxidant activities than pedicel and root extracts, due to higher levels of flavonoids and anthocyanins, especially in the purple species [8]. It has also been demonstrated that the Ayurvedic formulation Asthvarga, containing orchids as main component, has strong antioxidant capability, preventing DNA damage from oxidative stress [9]. Following these scientific achievements, the industrial exploitation of orchids for skin care purposes has been started. However, few phytochemical studies have been carried out on the inflorescences of European Orchidaceae $[10,11]$.

We chose to investigate Himantoglossum robertianum (Loisel.) P. Delforge (syn. Barlia robertiana) due to its large inflorescences, and because it can be easily propagated in vitro, making it exploitable as a source of bioactive substances without damaging natural populations [12]. H. robertianum is a Mediterranean orchid with scattered occurrence and large distribution area, spanning from Portugal and Morocco to Anatolia. Typical habitats include poor grassland, garrigue, scrub, and open woodland. The plant grows up to an altitude of $1700 \mathrm{~m}$, and blooms from January to April. It is called 'giant orchid', as it exceeds most European wild orchids by its large size, reaching a height of 50-80 cm [13]. The species is included in the Appendix II of the Convention on International Trade in Endangered Species of Wild Fauna and Flora (CITES), and as Least Concern on the French red list (UICN France et al. 2010). In Italy it is a protected entity at national level and is covered by total regional protection in different areas (https://www.actaplantarum.org/ipfi/floraz_base_map_prot.php?s=1147). However, despite its protected status, the species has been found to expand its presence across the Mediterranean distributional range [14].

In Turkey, the species is cultivated as ornamental plants in kitchen gardens [15], while in rural communities around Catania (Italy), it is roasted and eaten [16]. Similar uses are reported for the related species H. hircinum (L.) Spreng. (syn. H. affine), H. jankae Somlyay, Kreutz \& Óvári, and H. comperianum (Steven) P. Delforge, which in Iran are harvested for salep flour production, have a role in folk medicine, and their tubers are used for producing beverage and ice-cream [17].

H. robertianum has been studied for its essential oil [18], but there is little information on its phytochemistry and biological properties. Therefore, the aim of our study was to investigate the polyphenol composition and biological properties of flowers, in order to verify potentials for dermatological and cosmetic uses. The study included flower micro-morphological characterization, and the extraction of a polyphenolic fraction that was used for phytochemical investigations, in vitro cell-free experiments of enzyme inhibition, and the in vitro treatment of keratinocytes.

\section{Results}

\subsection{Flower Morphological Characterization}

The strongly scented flowers are arranged in dense spikes with 25-40 large flowers each, growing up to $15-30 \mathrm{~cm}$ (Figure 1A,B). Flowers are variable in color, from pink-purple to greenish-white, show an upper hood made up of 3 petals, and a large lower lip with a lighter spotted center and darker lip margins. The lip measures about $2.0 \mathrm{~cm}$, is divided into three lobes, and the central lobe is further subdivided. Considering color variability, we collected flowers showing a rather homogeneous purplish color in the labellum and sepals.

Flower samples observed under stereomicroscope showed three sepals and petals covering the fertile gynostemium (Figure 2A). The central petal, or labellum, differs from the lateral ones in color, shape, and size. It is composed by a median central region and two lateral zones (arms), showing epidermal cells with different colors and shapes (Figure 2A, Figure 3A). The labellum forms the spur 
that is probably involved in deceptive pollination, acting as a resting place for pollinators and as an osmophore involved in the emission of attractive odorants.
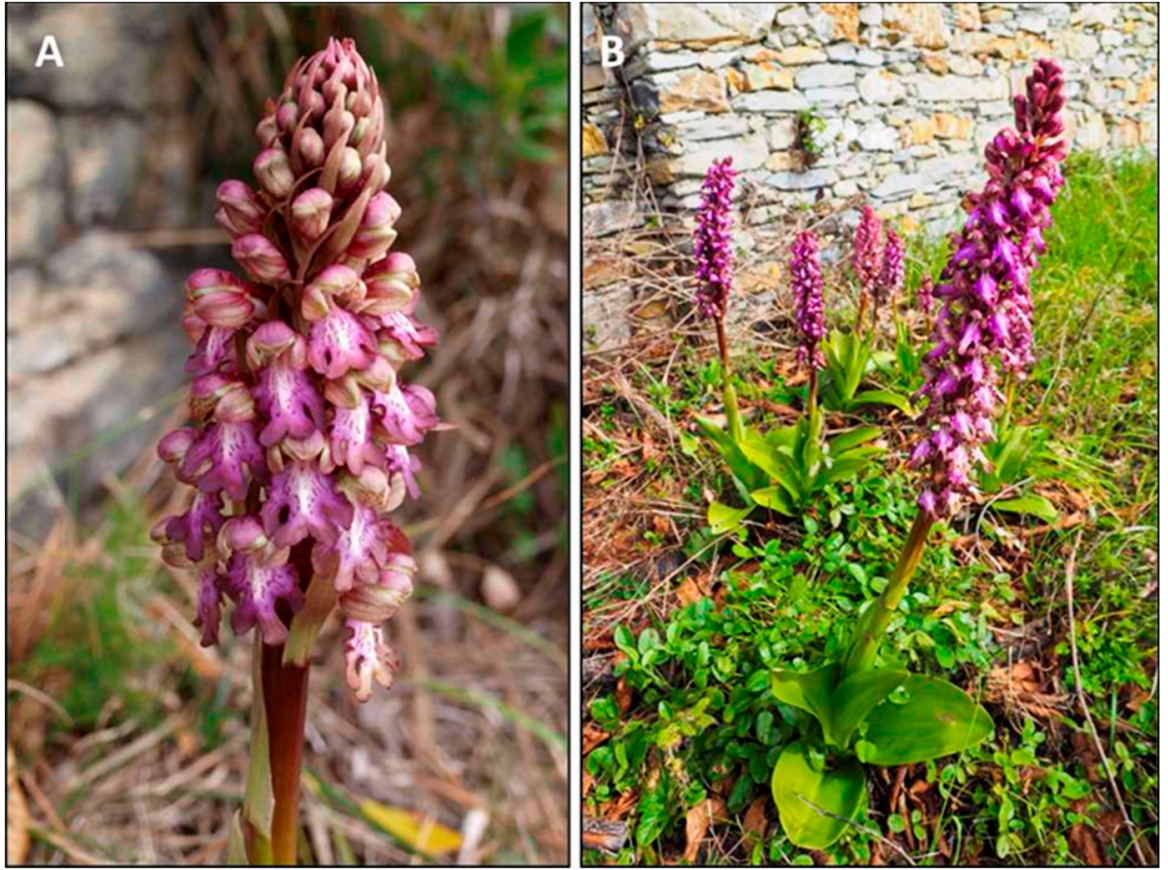

Figure 1. (A) Flower spike of H. robertianum. (B) Plant habitus in olive grove environment.
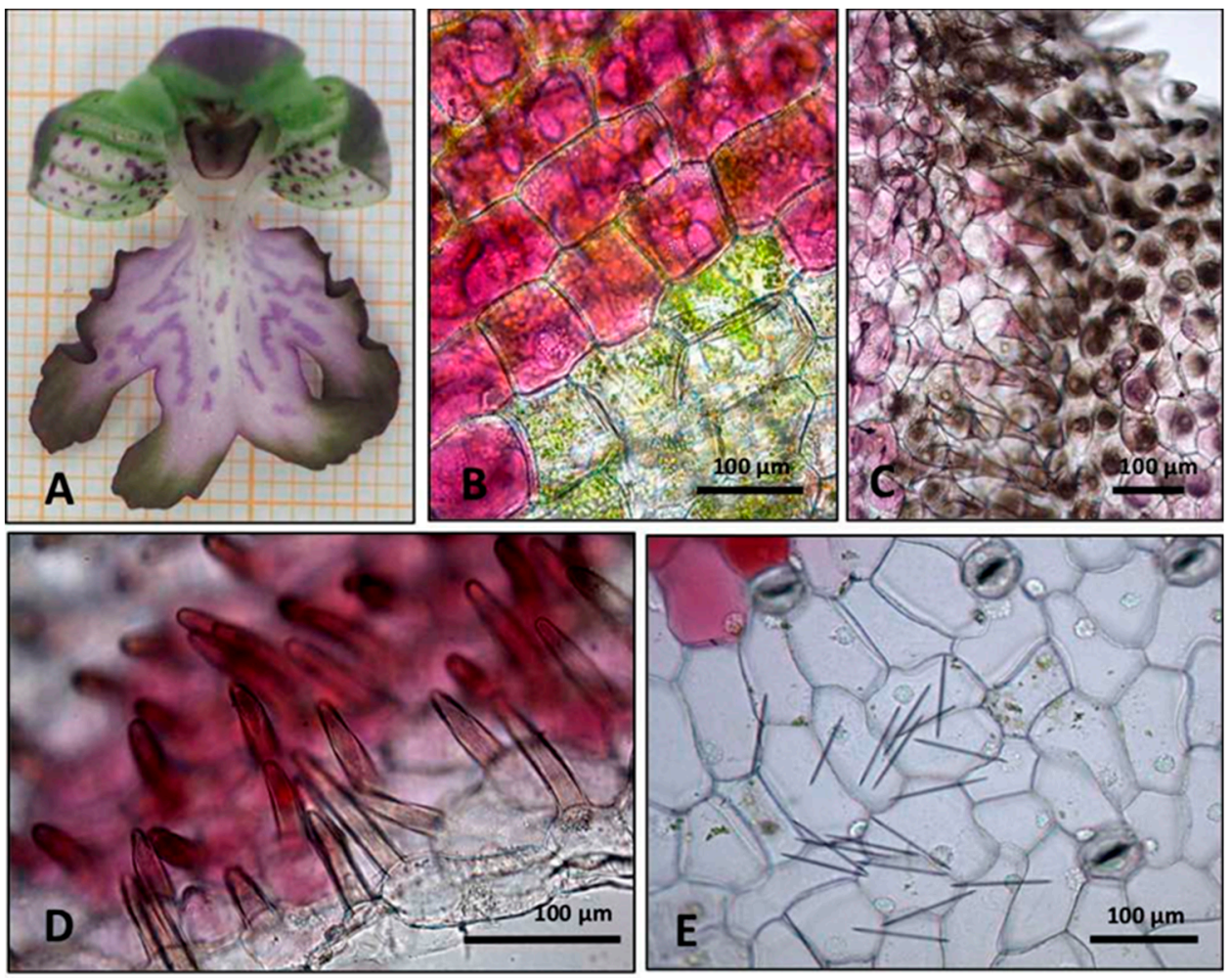

Figure 2. Stereomicroscope (A) and light microscope (B-E) pictures of the flower. (A) Total view showing three sepals, two petals, and a labellum. (B) Central portion of the labellum, showing purple, anthocyanin-rich cells interspersed among unpigmented cells. (C) Short papillose cells in an invagination of the medium-high portion of the labellum lateral arm. (D) Elongated pigmented papillae in the sub-stigmatic zone of the central labellum. (E) Stomata and raphides in the sepal. 

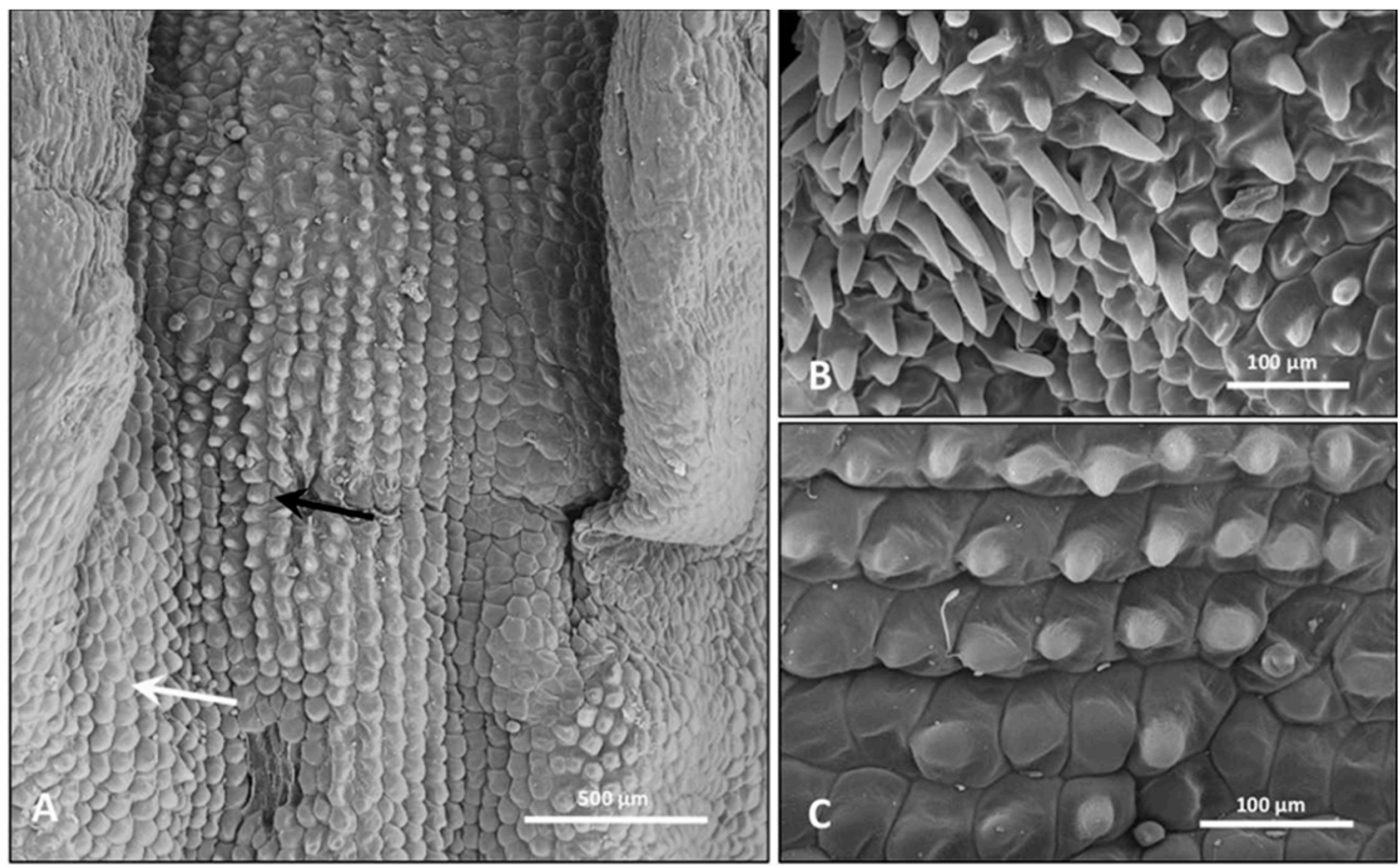

Figure 3. SEM micrographs of flower portions. (A) Overview of the central and lateral regions (arm) of the labellum in which two kinds of papillae are observed. Most prominent papillae were found in the central zone of the labellum (black arrow), while in the lateral zone the papillae become increasingly more flattened (white arrow). (B) Elongated papillae in the substigmatic zone of the central labellum.

(C) Magnified view of the labellum arm where gradual flattening of papillose cells is visible.

In sections observed under light microscopy, epidermal cells of the central region of the labellum appeared purple-red due to the presence of anthocyanins (Figure 2B). In the lateral region of the labellum, several short papillose cells, brown-purple in color, were found (Figure 2C) among more flattened, sub-polygonal cells covered by waxes (Figure 2C, Figure 3C). The sub-stigmatic zone of the central labellum showed outgrowths made of long papillose cells (Figure 2D, Figure 3B), possibly facilitating the emission of volatile compounds. Raphides and stomata were observed both in the sepals and in the labellum (Figure 2E).

\subsection{Phytochemical Characterization}

By ultrasound-assisted method, we obtained a hydroalcoholic flower extract (HFE) with a high extraction yield (8.28\%). A preliminary phytochemical screening (Table 1) revealed high total phenol content (243.7 mg GAE/100 $\mathrm{g}$ fresh weight, FW), with flavonoids representing the most abundant compounds (398.1 $\pm 9.8 \mathrm{mg} \mathrm{QE} / 100 \mathrm{~g} \mathrm{FW})$, and a lower presence of anthocyanins ( $4.89 \mathrm{mg} \mathrm{ChE} / 100 \mathrm{~g} \mathrm{FW}$ ). The higher content of flavan-3-ols determined by vanillin index $(3.31 \pm 0.032 \mathrm{mg}$ CatE/100 g FW), with respect to proanthocyanidins $(0.05 \pm 0.001 \mathrm{mg} C y E / 100 \mathrm{~g} \mathrm{FW})$, suggests the presence of polymeric compounds. This assumption was corroborated by the high value of the polymerization index (vanillin index/proanthocyanidin content ratio), yielding a rough estimate of the polyphenol polymerization degree. 
Table 1. Phytochemical screening of the hydroalcoholic Himantoglossum flower extract (HFE).

\begin{tabular}{cc}
\hline Phytochemical Screening & HFE \\
\hline Total phenols $\left(\mathrm{mg} \mathrm{GAE}^{1} / 100 \mathrm{~g} \mathrm{FW}\right)$ & $243.7 \pm 26.2$ \\
Flavonoids $\left(\mathrm{mg} \mathrm{QuE}^{2} / 100 \mathrm{~g} \mathrm{FW}\right)$ & $398.1 \pm 9.8$ \\
Anthocyanins $\left(\mathrm{mg} \mathrm{ChE}^{3} / 100 \mathrm{~g} \mathrm{FW}\right)$ & $4.89 \pm 0.05$ \\
Proanthocyanidins $\left(\mathrm{mg} \mathrm{CyE}^{4} / 100 \mathrm{~g} \mathrm{FW}\right)$ & $0.05 \pm 0.001$ \\
Vanillin index $\left(\mathrm{mg} \mathrm{CatE}^{5} / 100 \mathrm{gFW}\right)$ & $3.31 \pm 0.03^{6}$ \\
Polymerization index & 66.2
\end{tabular}

${ }^{1} \mathrm{GAE}=$ Gallic acid equivalents; ${ }^{2} \mathrm{QE}=$ Quercetin equivalents; ${ }^{3} \mathrm{ChE}=$ Chrysanthemin equivalents; ${ }^{4} \mathrm{CyE}=$ Cyanidin chloride equivalents; ${ }^{5}$ CatE $=$ Catechin equivalents. ${ }^{6}$ Data are expressed as means \pm standard deviation (S.D.) of three independent experiments.

The RP-LC-DAD analysis confirmed what was observed in the preliminary phytochemical screening, allowing us to identify and quantify 17 compounds, with a total polyphenol content of $144.5 \mathrm{mg} / 100 \mathrm{~g}$ FW (Figure 4).

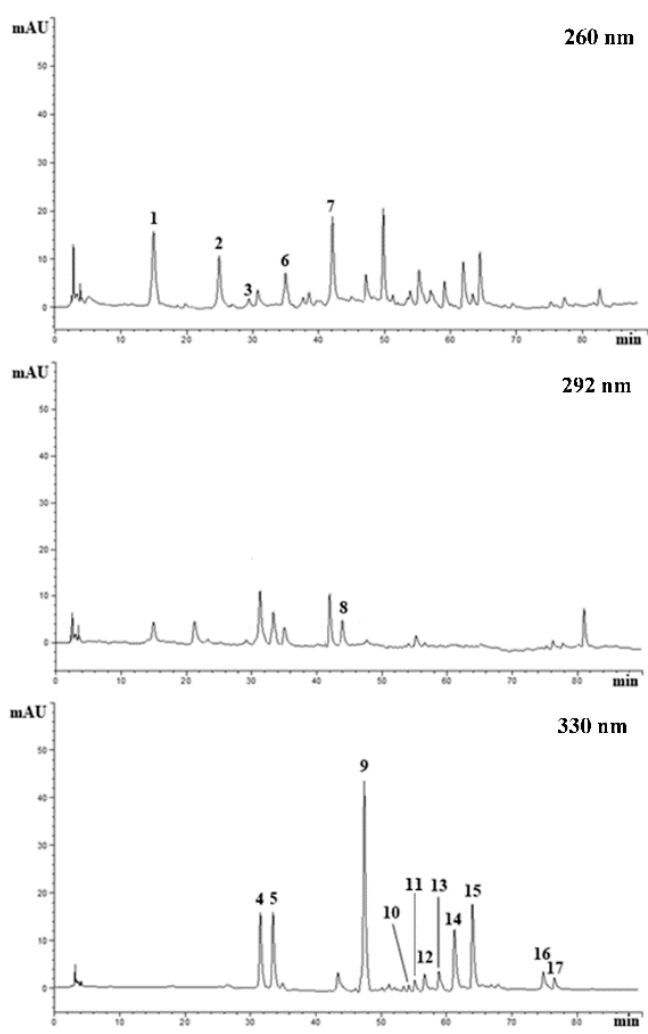

(A)

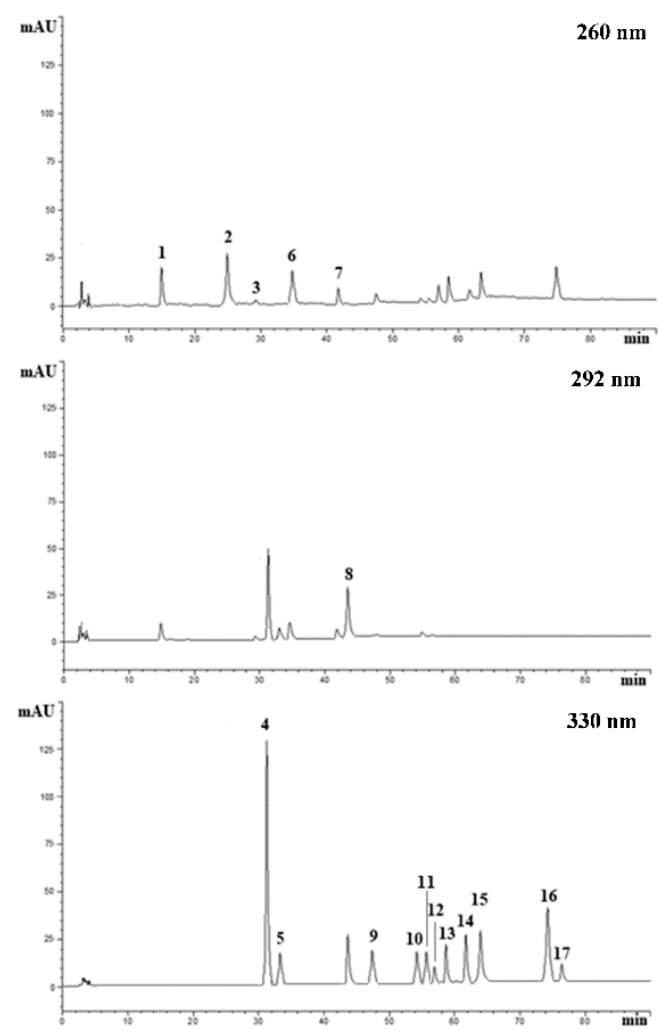

(B)

Figure 4. Representative RP-LC-DAD chromatogram of HFE (Panel A) and reference standard mix $10 \mu \mathrm{g} / \mathrm{mL}$ (Panel B), acquired at 260, 292, and $330 \mathrm{~nm}$. Peak numbers correspond to compounds listed in Tables 2 and 4.

Among polyphenols, flavonoids represent the most abundant compounds (42.91\%), followed by scopoletin, the only coumarin identified (33.79\%), and phenolic acids $(23.3 \%)$. Interestingly, flavonoids belong to only two subclasses, i.e., flavones $(79.85 \%)$ and flavan-3-ols $(20.15 \%)$. The most abundant flavonoid was kaempferol-3-O-rutinoside ( $21.1 \mathrm{mg} / 100 \mathrm{~g} \mathrm{FW})$, while among phenolic acids, the most abundant was caffeic acid (11.5 g/100 FW) (Table 2). 
Table 2. HFE polyphenol profile.

\begin{tabular}{|c|c|c|c|c|}
\hline Peak n. ${ }^{1}$ & Compound & $R_{t}{ }^{2}(\min )$ & $\lambda_{\max }(\mathrm{nm})$ & $\mathrm{mg} / 100 \mathrm{~g} \mathrm{FW}^{3}$ \\
\hline \multicolumn{5}{|c|}{ Phenolic acids } \\
\hline 1 & Protocatecuic acid & 15.057 & $260 ; 294$ & $7.8 \pm 0.06$ \\
\hline 2 & Hydroxybenzoic acid & 25.543 & 255 & $0.09 \pm 0.001$ \\
\hline 4 & Chlorogenic acid & 31.399 & $294 ; 326$ & $10.85 \pm 0.44$ \\
\hline 5 & Caffeic acid & 33.614 & $232 ; 323$ & $11.52 \pm 0.37$ \\
\hline 6 & Vanillic acid & 35.252 & $260 ; 292$ & $0.08 \pm 0.002$ \\
\hline \multicolumn{5}{|c|}{ Flavan-3-ols } \\
\hline 3 & Catechin & 29.451 & $234 ; 279$ & $2.63 \pm 0.02$ \\
\hline 7 & Epicatechin & 42.062 & $232 ; 280$ & $9.87 \pm 0.38$ \\
\hline \multicolumn{5}{|c|}{ Flavones } \\
\hline 10 & Isovitexin & 55.300 & $270 ; 337$ & $3.82 \pm 0.04$ \\
\hline 11 & Naringenin-7-O-glucoside & 55.878 & $284 ; 340$ & $0.98 \pm 0.02$ \\
\hline 12 & Vitexin & 57.145 & $268 ; 338$ & $5.47 \pm 0.05$ \\
\hline 13 & Rutin & 59.281 & $256 ; 356$ & $5.08 \pm 0.03$ \\
\hline 14 & Kaempferol-3-O-rutinoside & 61.975 & $266 ; 348$ & $21.1 \pm 0.25$ \\
\hline 15 & Roifolin & 64.619 & $266 ; 338$ & $9.23 \pm 0.08$ \\
\hline 16 & Luteolin & 74.693 & $254 ; 350$ & $0.86 \pm 0.04$ \\
\hline 17 & Apigenin & 76.417 & $236 ; 338$ & $3.01 \pm 0.07$ \\
\hline \multicolumn{5}{|c|}{ Coumarins } \\
\hline 9 & Scopoletin & 47.373 & $296 ; 344$ & $48.85 \pm 0.48$ \\
\hline
\end{tabular}

${ }^{1}$ Peak numbers refer to Figure $4 .{ }^{2}$ Rt, Retention time. ${ }^{3}$ Data are expressed as $\mathrm{mg} / 100 \mathrm{~g}$ FW, and as means \pm S.D. of three independent experiments $(n=3)$.

\subsection{Antioxidant and Free-Radical Scavenging Activity}

In order to evaluate the antioxidant and free-radical scavenging activity of HFE, various in vitro cell-free assays, based on different environments and reaction mechanisms, were carried out. All assays showed dose-dependent $(\mathrm{R} 2 \geq 0.99)$ antioxidant and free-radical scavenging activities, with the following order of potency ORAC $>$ FRAP $>$ TEAC $>\beta$-carotene bleaching $>$ DPPH $>$ Iron-chelating activity (Table 3). These data indicate that HFE can counteract different charged free-radical types, especially peroxyl ones.

Table 3. HFE antioxidant and free-radical scavenging activities.

\begin{tabular}{|c|c|}
\hline \multirow{2}{*}{ Antioxidant Assay } & HFE \\
\hline & $\mathrm{IC}_{50}{ }^{1} \mu \mathrm{g} / \mathrm{mL}\left(95 \%\right.$ C.L. $\left.^{2}\right)$ \\
\hline $\mathrm{DPPH}$ & $211.1(181.1-245.3)^{3}$ \\
\hline FRAP & $8.85(7.69-10.18)$ \\
\hline TEAC & $25.04(20.41-30.71)$ \\
\hline ORAC & $2.52(2.19-2.9)$ \\
\hline$\beta$-carotene bleaching & $31.43(22.12-44.66)$ \\
\hline Iron-chelating activity & $440.8(330.1-588.6)$ \\
\hline
\end{tabular}

${ }^{1} \mathrm{IC}_{50}=$ half-maximal inhibitory concentration; ${ }^{2}$ C.L. $=$ Confidence limits. ${ }^{3}$ Data are expressed as means \pm S.D. of three independent experiments $(n=3)$.

\subsection{Effects of HFE on Keratinocytes and Skin Enzymes}

Effects of HFE on cell viability were preventively tested by the MTT assay, finding $\mathrm{IC}_{05}>500$ and $\mathrm{IC}_{50}>1000 \mu \mathrm{g} / \mathrm{mL}$. Therefore, in order to keep HFE at subtoxic levels, all experiments were conducted by using $500 \mu \mathrm{g} / \mathrm{mL}$ as the highest concentration.

In order to evaluate the antioxidant potential of HFE directly on cells, we pre-exposed HaCaT cells to HFE for $24 \mathrm{~h}$, and then to HFE combined with $\mathrm{H}_{2} \mathrm{O}_{2}$ for a further $24 \mathrm{~h}$. Controls were run by incubating cells with HFE alone for $48 \mathrm{~h}$, or with $\mathrm{H}_{2} \mathrm{O}_{2}$ alone for $24 \mathrm{~h}$. At the end of incubations, cell 
viability was assessed by MTT assay. The complex of data showed that $500 \mu \mathrm{g} / \mathrm{mL}$ HFE induced a significant protection against the injurious effects of $500 \mu \mathrm{M} \mathrm{H}_{2} \mathrm{O}_{2}$ (Figure $5 \mathrm{~A}$ ).
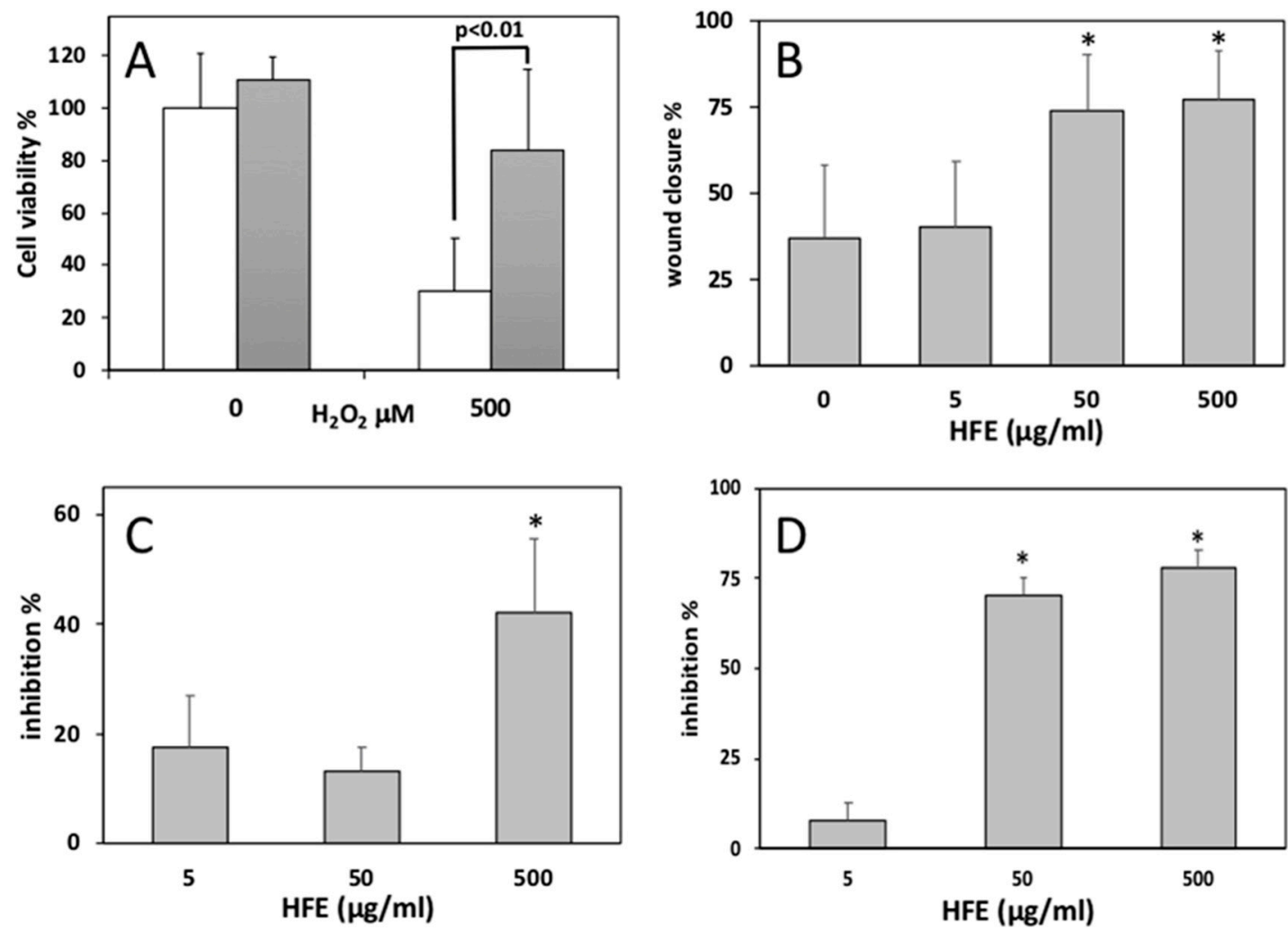

Figure 5. Biological activities of HFE. All data are expressed as means \pm S.D. (A) Protective effect of pre-incubation with $500 \mu \mathrm{g} / \mathrm{mL}$ HFE on cell viability reduction induced by $500 \mu \mathrm{M} \mathrm{H}_{2} \mathrm{O}_{2}$, evaluated by MTT assay on HaCaT keratinocytes. Data are formazan absorbance at $570 \mathrm{~nm}$ standardized as percent of control $(n=8)$. Differences between means have been evaluated by $\mathrm{t}$ test. (B) Increased wound closure induced by HFE in a scratch wound healing assay conducted in vitro on HaCaT keratinocytes. Data are wound closures measured at $24 \mathrm{~h}$ since wounding, and expressed as percent of total closure $(n=30-200) .{ }^{*}=p<0.01$ according to Bonferroni test. (C) In vitro inhibition of porcine pancreas elastase by $500 \mu \mathrm{g} / \mathrm{mL}$ HFE. Data are percent inhibition obtained from absorbances at $410 \mathrm{~nm}(n=3$ independent measures). Statistical comparisons as in B. (D) In vitro inhibition of Clostridium histolyticum collagenase by HFE. Data are percent inhibition obtained from enzyme kinetics derived from absorbances at $345 \mathrm{~nm}$, at the time points of 0 and $15 \mathrm{~min}$ ( $n=3$ independent measures). Statistical comparisons as in B.

The scratch wound assay, conducted for $48 \mathrm{~h}$ on $\mathrm{HaCaT}$ cells, showed a significant increase of cell migration after incubation with 50 and $500 \mu \mathrm{g} / \mathrm{mL}$ HFE (Figure 5B).

Finally, we performed cell-free assays to verify the ability of HFE to inhibit two major enzymes involved in skin extracellular matrix degradation, viz. elastase and collagenase. In the elastase test, a significant average inhibition of $42 \%$ was found with $500 \mu \mathrm{g} / \mathrm{mL}$ HFE (Figure 5C), while in the collagenase test significant average inhibitions of $70 \%$ and $78 \%$ were obtained with 50 and $500 \mu \mathrm{g} / \mathrm{mL}$ HFE, respectively (Figure 5D).

\section{Discussion}

The polyphenol characterization of HFE showed that the extract is very rich in flavonoids, scopoletin, and phenolic acids. It is well known that the antioxidant and free-radical scavenging properties of polyphenols are directly correlated with the number of hydroxyl groups linked to the phenolic structure, and indirectly correlated with their glycosylation degree [19]. Flavones are the most abundant sub-class of flavonoids in HFE, but they are mostly glycosylated, and therefore, they 
should only marginally contribute to the observed antioxidant and free-radical scavenging activities. In contrast, flavan-3-ols like catechin and epicatechin, also having catechol structure, could play a primary role in antioxidant activities, together with major polyhydroxylated phenolic acids like protocatecuic, chlorogenic, and caffeic acids.

Scopoletin, as previously demonstrated, showed a good scavenging ability against $\mathrm{ABTS}^{\bullet}{ }^{\bullet}$, but was not effective against other charged radicals, while it showed only a weak antioxidant activity. Also, in coumarins the catechol group markedly contributes to the antioxidant activity, while glycosylation adversely affects it. In addition, the $\alpha$-pyrone ring makes coumarins more hydrophobic than phenolic acids, and therefore more reactive with respect to lipid peroxidation [20]. In conclusion, the complex of phytochemicals suggests that HFE can act as a powerful scavenger of different charged radicals.

In parallel with phytochemical characterization and antioxidant evaluation, skin-preserving properties have been clearly suggested by the complex of our bioassays. Significant protection of keratinocytes against injurious effects has been found after double exposure to $\mathrm{HFE}$ and $\mathrm{H}_{2} \mathrm{O}_{2}$ as the oxidant agent, but only at high HFE doses. The lack of a pan-antioxidant protection could reflect the known tendency of some polyphenols, e.g., flavonoids, to elicit pro-oxidant activities under specific redox conditions [21,22]. However, polyphenols are also widely known to exert antioxidant effects, as fully confirmed in this study by the panel of specific assays. Hence, the polyphenols of H. robertianum, used at proper doses, could support skin redox balance processes, thus contributing to prevent or counteract oxidative-related dysfunctions, especially those leading to skin ageing. This kind of activity should be further potentiated by stimulation of keratinocyte mobilization, revealed by our scratch wound assay, suggesting a support to skin repair following injury or degenerative processes.

The elastase inhibition induced by HFE rates at average levels among plant extracts, while collagenase inhibition approaches topmost values obtained with polyphenol-rich white tea extract [23]. Collagen and elastin are the most abundant protein constituents of the dermal extracellular matrix, being primarily affected by photoaging and other oxidative processes that cause wrinkles and reduction in skin thickness [24]. Hence, the results obtained with HFE on matrix degrading enzymes make this orchid-derived product a very promising ingredient for skin aging remedies.

Orchids are in general protected plant species, but the development of protocols for in vitro propagation is making these plants exploitable for industrial purposes without affecting wild populations [25]. These techniques have been applied also to $H$. robertianum, through protoplast isolation and in vitro propagation from asymbiotic seed germination [26,27]. Hence, the giant orchid $H$. robertianum shows remarkable biological properties of its flower extract and can be exploited in environment-friendly mode, suggesting its possible use for post-traumatic and post-inflammatory skin repair, antiaging treatments, and skin preserving applications.

\section{Materials and Methods}

\subsection{Plant Materials}

Flowers of $H$. robertianum were gathered by LC and MB from wild populations growing at Taggia $\left(43^{\circ} 52^{\prime} 05.2^{\prime \prime} \mathrm{N}, 7^{\circ} 50^{\prime} 14.6^{\prime \prime} \mathrm{E}\right)$, and Carpasio $\left(43^{\circ} 57^{\prime} 24.8^{\prime \prime} \mathrm{N}, 7^{\circ} 50^{\prime} 38.7^{\prime \prime} \mathrm{E}\right)$ (Imperia, Liguria, Italy) from February to May 2018. Sampling of the species, protected under law, was allowed by the Ligurian Region Government with act n. 363/29-01-2018. Only flowers were carefully sampled from resident plants, in order to minimize damage to populations. The species has a quite distinctive habitus and size, and it was determined in the field by LC and MB, and two voucher specimens (one from each sampling site) were deposited at the Herbarium of DISTAV, University of Genova, Genova, Italy (number: GE 1038).

\subsection{Reagents and Cells}

All reagents were purchased from Sigma Aldrich (Milan, Italy), unless otherwise indicated. The HaCaT human keratinocyte cell line was purchased from the Biological Bank of the Azienda 
Ospedaliera Universitaria San Martino-IST, Genova, Italy. Cells were cultured at $37^{\circ} \mathrm{C}$, in a $5 \% \mathrm{CO}_{2}$, humidified atmosphere, using Dulbecco's Modified Eagle Medium (DMEM, EuroClone, Milan, Italy) enriched with $10 \%(v / v)$ FBS, $1 \%$ glutamine, and $1 \%$ antibiotic.

\subsection{Light and Scanning Electron Microscopy Analyses}

Flower portions were observed by a Leica M205C stereomicroscope, coupled with EC3 camera and LAS EZ V1.6.0 image analysis software. Epidermal peels of the fresh flowers were mounted on glass slides and observed by a Leica DM 2000 transmission-light microscope coupled with a computerdriven DFC 320 camera (Leica Microsystems, Wetzlar, Germany).

For Scanning Electron Microscope (SEM) analyses, small flower pieces were fixed in Finefix working solution (Milestone s.r.l., Bergamo, Italy) with $70 \%$ ethanol, incubated overnight at $4{ }^{\circ} \mathrm{C}$, dehydrated by ethanol series (70-100\%) at 60 min intervals, and dried using a Critical Point Dryer Processor (K850CPD 2M Strumenti S.r.l., Roma, Italy) [28]. Dried samples were positioned on aluminum stubs, covered with 10nm gold particles, and observed in a VEGA3-Tescan-type LMU microscope (Tescan Orsay Holding, a.s., Brno, Czech Republic), at an accelerating voltage of $20 \mathrm{kV}$.

\subsection{Hydroalcoholic Flower Extract (HFE) Preparation}

Flowers were gently grounded by a blade mill (IKA ${ }^{\circledR}$ A11 basic analytical mill) under liquid nitrogen. One hundred milliliters of $70 \%$ ethanol were added to $10 \mathrm{~g}$ of powdered sample mixing for $3 \mathrm{~min}$. The extraction was carried out three times by sonication in an ice-cold bath for $5 \mathrm{~min}$ using a $3 \mathrm{~mm}$ titanium probe, set to 200W power and 30\% amplitude signal (Vibra CellTM Sonics Materials inc., Danbury, CT, USA). Thereafter, the sample was centrifuged at $3000 \mathrm{rpm}$ for $15 \mathrm{~min}$ (NEYA 10R, REMI, Carpi, Italy) and the supernatant was collected and evaporated by rotary evaporator (BUCHI R-205, Cornaredo, Italy). Dry HFE was dissolved in 70\% ethanol in order to obtain a $50 \mathrm{mg} / \mathrm{mL}$ stock solution, which was properly diluted to carry out polyphenol characterization, antioxidant assays, cell-free bioassays, and cell treatments.

\subsection{Chemical Characterization}

\subsubsection{Total Phenols}

Total phenols content was established by Folin-Ciocalteu assay as previously reported [29]. The absorbance was recorded at $786 \mathrm{~nm}$ using an UV-Vis spectrophotometer (Shimadzu UV-1601, Kyoto, Japan). Results were expressed as mg of gallic acid equivalents (GAE)/100 g of sample fresh weight (FW).

\subsubsection{Flavonoids}

Total flavonoids content of HFE $(0.625-10 \mathrm{mg} / \mathrm{mL})$ was determined colorimetrically using an UV-Vis Spectrophotometer (Shimadzu UV-1601) as previously reported [19]. Quercetin (0.125-1.0 mg/mL) was used as reference compound. Flavonoid content was expressed as $\mathrm{mg}$ of quercetin equivalents (QE)/100 g of sample FW.

\subsubsection{Vanillin Index}

The proanthocyanidin and anthocyanin contents were determined as previously reported [30], recording the absorbance of sample by an UV-Vis spectrophotometer (Shimadzu UV-1601, Kyoto, Japan) at $500 \mathrm{~nm}$ against a blank. Catechin was used as reference compound $(0-500 \mu \mathrm{g} / \mathrm{mL})$ and results were expressed as $\mathrm{mg}$ of catechin equivalent (CatE)/100 mg of sample FW.

\subsubsection{Proanthocyanindin and Anthocyanin Content}

The proanthocyanidin content was determined by an UV-Vis spectrophotometer (Shimadzu UV-1601, Kyoto, Japan), as previously reported [30,31]. Results were expressed as mg of Cyanidin 
chloride equivalents (CyE)/100 g of sample FW and Chrysanthemin (Cyanidin-3-O-glucoside) chloride equivalents (ChE)/100 g of sample FW, respectively.

4.5.5. Polyphenol Profile by Reversed Phase Liquid Chromatography with Diode Array Detection (RP-LC-DAD)

The qualitative and quantitative determination of polyphenols in HFE was carried out as previously reported [32]. An Agilent high performance liquid chromatography system (1100 series, Santa Clara, CA, USA), equipped with a photodiode-array detector (DAD, G1315), was used. Briefly, the chromatographic separation was carried out by a $5 \mu \mathrm{m}, 250 \mathrm{~mm} \times 4.6 \mathrm{~mm}$ ODS3 Prodigy column (Phenomenex, Torrance, CA, USA), maintained at $25^{\circ} \mathrm{C}$, with solvent A (water/acetic acid, 97:3, v/v) and solvent $\mathrm{B}$ (methanol). The gradient elution was: 0-3 $\mathrm{min}, 0 \% \mathrm{~B} ; 3-9 \mathrm{~min}, 3 \% \mathrm{~B} ; 9-24 \mathrm{~min}, 12 \% \mathrm{~B}$; 24-30 min, 20\% B; 30-33 min, 20\% B; 33-43 min, 30\% B; 43-63 min, 50\% B; 63-66 min, 50\% B; 66-76 min, $60 \% \mathrm{~B} ; 76-81 \mathrm{~min}, 60 \% \mathrm{~B} ; 81-86 \mathrm{~min}, 0 \% \mathrm{~B}$ and equilibrated $4 \mathrm{~min}$ for a total run time of $90 \mathrm{~min}$. Flow rate and injection volume was $1.0 \mathrm{~mL} / \mathrm{min}$ and $50 \mu \mathrm{L}$, respectively. UV-Vis spectra of polyphenols were recorded from 190 to $400 \mathrm{~nm}$. Peak identity was confirmed by comparing the retention time and the absorption spectra with those of pure ( $\geq 99 \%$ ) commercially available standards (Extrasynthese, Genay, France). Chromatograms were acquired at 260 and $292 \mathrm{~nm}$ for phenolic acids and flavan-3-ols, and at $330 \mathrm{~nm}$ for flavones and coumarins. Quantitative analysis was carried out using external calibration curves of reference compounds (concentration range $0.1-20 \mu \mathrm{g} / \mathrm{mL}$ ) (Table 4).

Table 4. Reference compounds used for quantitative analysis.

\begin{tabular}{ccccc}
\hline Peak n. ${ }^{\mathbf{1}}$ & Compound & $\mathbf{R}_{\mathbf{t}}(\mathbf{m i n})$ & $\boldsymbol{\lambda}_{\mathbf{m a x}} \mathbf{( \mathbf { n m } )}$ & $\begin{array}{c}\text { Regression } \\
\text { Coefficient } \\
\left(\mathbf{R}^{\mathbf{2}}\right)\end{array}$ \\
\hline 1 & Protocatecuic acid & 15.055 & $260 ; 294$ & 0.9999 \\
2 & Hydroxybenzoic acid & 25.545 & 255 & 0.9997 \\
3 & Catechin & 29.453 & $234 ; 279$ & 0.9997 \\
4 & Chlorogenic acid & 31.401 & $294 ; 326$ & 0.9999 \\
5 & Caffeic acid & 33.617 & $232 ; 323$ & 0.9998 \\
6 & Vanillic acid & 35.254 & $260 ; 292$ & 0.9996 \\
7 & Epicatechin & 42.065 & $232 ; 280$ & 0.9999 \\
8 & Coumaric acid & 43.813 & $233 ; 310$ & 0.9999 \\
9 & Scopoletin & 47.375 & $296 ; 344$ & 0.9999 \\
10 & Isovitexin & 55.302 & $270 ; 337$ & 0.9997 \\
11 & Naringenin-7-O-glucoside & 55.881 & $284 ; 340$ & 0.9998 \\
12 & Vitexin & 57.145 & $268 ; 338$ & 0.9996 \\
13 & Rutin & 59.282 & $256 ; 356$ & 0.9997 \\
14 & Kaempferol-3-O-rutinoside & 61.977 & $266 ; 348$ & 0.9998 \\
15 & Roifolin & 64.620 & $266 ; 338$ & 0.9999 \\
16 & Luteolin & 74.695 & $254 ; 350$ & 0.9999 \\
17 & Apigenin & 76.418 & $236 ; 338$ & 0.9998 \\
\hline
\end{tabular}

${ }^{1}$ Peak numbers refer to Figure 4.

\subsection{Antioxidant and Free-Radical Scavenging Activities}

\subsubsection{Scavenging Activity of 2,2-diphenyl-1-picrylhydrazyl (DPPH) Free Radical}

The DPPH free radical scavenging activity of HFE (31.25-500 $\mu \mathrm{g} / \mathrm{mL})$ was evaluated using an UV-Vis Spectrophotometer (Shimadzu UV-1601, Kyoto, Japan), as previously reported [19]. The results were expressed as inhibition (\%) of the radical activity calculating the half-maximal inhibitory concentration $\left(\mathrm{IC}_{50}\right)$ with the respective confidence limits (C.L.) at $95 \%$. 


\subsubsection{Trolox Equivalent Antioxidant Capacity (TEAC)}

The antioxidant activity against 2,2'-azino-bis(3-ethylbenzothiazoline-6-sulphonic acid) (ABTS) radical was carried out as previously reported [33]. Fifty microliters of HFE (6.25-100 $\mu \mathrm{g} / \mathrm{mL})$ were added into $1 \mathrm{~mL}$ of TEAC reagent and incubated in dark at RT for $6 \mathrm{~min}$. Absorbance was recorded at $734 \mathrm{~nm}$ with an UV-Vis Spectrophotometer (Shimadzu UV-1601, Kyoto, Japan). Results were expressed as inhibition (\%) of the radical activity calculating the half-maximal inhibitory concentration $\left(\mathrm{IC}_{50}\right)$ with the respective C.L. at $95 \%$.

\subsubsection{Ferric-Reducing Antioxidant Potential (FRAP)}

The free-radical scavenging capacity against 2,4,6-tris(2-pyridyl)-s-triazine (TPTZ) radical was performed according to a previous study [33]. Briefly, $25 \mu \mathrm{L}$ of HFE $(1.25-20 \mu \mathrm{g} / \mathrm{mL})$ was added to $1.5 \mathrm{~mL}$ of daily fresh FRAP reagent pre-warmed at $37^{\circ} \mathrm{C}$, and incubated for $4 \mathrm{~min}$ at RT. The absorbance was recorded at $593 \mathrm{~nm}$ by an UV-VIS Spectrophotometer (Shimadzu UV-1601, Kyoto, Japan), and results were expressed as inhibition (\%) of the radical activity calculating the half-maximal inhibitory concentration $\left(\mathrm{IC}_{50}\right)$ with the respective C.L. at $95 \%$.

\subsubsection{Oxygen Radical Absorbance Capacity (ORAC)}

ORAC was evaluated as previously reported [19]. Briefly, $20 \mu \mathrm{L}$ of HFE $(0.3125-10.0 \mu \mathrm{g} / \mathrm{mL})$ diluted in $75 \mathrm{mM}$ phosphate buffer solution ( $\mathrm{pH} 7.4$ ) was mixed with $120 \mu \mathrm{L}$ of fresh daily $117 \mathrm{nM}$ fluorescein solution. After $15 \mathrm{~min}$ incubation at $37^{\circ} \mathrm{C}, 60 \mu \mathrm{L}$ of fresh daily AAPH solution $(40 \mathrm{mM})$ was added. The fluorescence was monitored every $30 \mathrm{~s}$ for $90 \mathrm{~min}\left(\lambda_{\mathrm{ex}} 485 \mathrm{~nm} ; \lambda_{\mathrm{em}} 520 \mathrm{~nm}\right)$ using a fluorescence plate reader (Fluostar Omega, BMGLabtech, Ortenberg, Germany). Phosphate buffer was used as negative control while trolox was used as reference standard $(10-100 \mu \mathrm{M})$. Results were expressed as inhibition (\%) of the radical activity calculating the half-maximal inhibitory concentration $\left(\mathrm{IC}_{50}\right)$ with the respective C.L. at $95 \%$.

\subsection{5. $\beta$-Carotene Bleaching Assay}

The $\beta$-carotene bleaching assay was performed as previously described [19]. Aliquots of the fresh $\beta$-carotene emulsion $(8.0 \mathrm{~mL})$ were mixed with $320 \mu \mathrm{L}$ of HFE solutions $(12.50-200 \mu \mathrm{g} / \mathrm{mL})$. An emulsion without $\beta$-carotene was used as negative control. The absorbance was recorded at $470 \mathrm{~nm}$ at the starting time $(t=0)$, and then incubated at $50{ }^{\circ} \mathrm{C}$ in a water bath for $120 \mathrm{~min}$, recording the absorbance every $20 \mathrm{~min}$. Butylated-hydroxytoluene (BHT) $1 \mathrm{mg} / \mathrm{mL}$ was used as positive control. The antioxidant activity was expressed as inhibition (\%) of the $\beta$-carotene bleaching calculating the half-maximal inhibitory concentration $\left(\mathrm{IC}_{50}\right)$ with the respective C.L. at $95 \%$.

\subsubsection{Iron-Chelating Activity}

The iron-chelating activity of HFE was evaluated according to a previous study [34], with some modifications. Briefly, $50 \mu \mathrm{L}$ of $\mathrm{FeCl}_{2} \cdot 4 \mathrm{H}_{2} \mathrm{O}$ solution $(2.0 \mathrm{mM})$ was added to $100 \mu \mathrm{L}$ of HFE $(62.5-100 \mu \mathrm{g} / \mathrm{mL})$ incubating at RT for $5 \mathrm{~min}$. After that, $100 \mu \mathrm{L}$ of ferrozine solution $(5 \mathrm{mM})$ was added to the reaction mixture and the sample solution diluted to $3 \mathrm{~mL}$ with deionized water, mixed and incubated for $10 \mathrm{~min}$ at RT. The absorbance was read at $562 \mathrm{~nm}$ using an UV-VIS Spectrophotometer (Shimadzu UV-1601, Kyoto, Japan). Results were expressed as inhibition (\%) of the $\mathrm{Fe}^{2+}$ chelating capacity calculating the half-maximal inhibitory concentration $\left(\mathrm{IC}_{50}\right)$ with the respective C.L. at $95 \%$.

\subsection{Biological Assays}

\subsubsection{Collagenase and Elastase Inhibition Assays}

The elastase and collagenase assays were performed according to a previously-reported method [35]. Briefly, elastase (EC 3.4.21.36) inhibition was evaluated in a reaction 
mixture containing $200 \mathrm{mM}$ tris(hydroxymethyl)aminomethane (TRIS) $\mathrm{pH} 8.0,10 \mathrm{mM}$ $\mathrm{N}$-succinyl-Ala-Ala-Ala-p-nitroanilide (Sigma-Aldrich, cat. S4760), 4 units/mL of elastase from porcine pancreas (Sigma-Aldrich, E1250), and serial water dilutions of HFE stock solutions in 30\% ethanol (final concentrations: 5, 50,500 $\mu \mathrm{g} / \mathrm{mL}$ ). After incubation at RT for $10 \mathrm{~min}$, plates were read at $410 \mathrm{~nm}$ on a Varian Cary-50 Bio spectrophotometer (Agilent, Milan, Italy).

Collagenase (EC 3.4.24.3) inhibition was assayed in a mix containing 0.16 units $/ \mathrm{mL}$ of collagenase from Clostridium histolyticum (Sigma-Aldrich, cat. MAK293B), 20\% N-[3-(2-furyl)acryloyl]-L-leucyl-glycyl-L-prolyl-L-alanine (FALGPA, substrate, MAK293C), 74\% collagenase assay buffer (MAK293A), and water dilutions of HFE stock solution in 60\% ethanol, to reach the indicated concentrations. Plates were read at $345 \mathrm{~nm}$, at $37^{\circ} \mathrm{C}$, for $15 \mathrm{~min}$ in kinetic mode.

\subsubsection{Cytotoxicity and Cytoprotection Assays}

Effects of HFE on cell viability were assessed by the 3-(4,5-dimethylthiazol-2-yl)-2,5diphenyltetrazolium bromide (MTT) assay. HaCaT were settled on 96-well plate for $24 \mathrm{~h}$, incubated with 5,50 , or $500 \mu \mathrm{g} / \mathrm{mL} \mathrm{HFE}$ for $24 \mathrm{~h}$, processed for MTT staining, and read at $570 \mathrm{~nm}$. Absorbance data were used to obtain dose-response curves and $\mathrm{IC}_{50}$ values.

For the assay of HFE cytoprotective properties, HaCaT were settled as above in 96-wells plates, preincubated for $24 \mathrm{~h}$ with 5, 50, or $500 \mu \mathrm{g} / \mathrm{mL} \mathrm{HFE}$, and then co-incubated for further $24 \mathrm{~h}$ with the above HFE doses combined with 500, 750, or $1000 \mu \mathrm{M} \mathrm{H}_{2} \mathrm{O}_{2}$. Cell viability was then determined by MTT test. Results were expressed as the percentage of viable or dead cells (ratio of unstained or stained cells to the total number of cells, respectively).

\subsubsection{In Vitro Wound Healing Assay}

The migration rate of HaCat cells exposed to HFE was assessed by the scratch wound assay method as reported by Muniandy et al. [36]. Briefly, cells were seeded on 12-well plates $\left(2 \times 10^{5}\right.$ cells/well), grown to monolayer, and wounded with a $100 \mu \mathrm{L}$ pipette tip. One well was immediately fixed in Finefix working solution and stained with $\mathrm{TBO} 0.1 \%$, to represent the T0 sample. Negative control was exposed to medium without serum, and control to complete medium. The remaining wells were exposed for $48 \mathrm{~h}$ to 5, 50, or $500 \mu \mathrm{g} / \mathrm{mL}$ HFE. After incubation, cells were washed with PBS, fixed, and stained as above. Images of wounds were taken with a Leica M205 C stereomicroscope coupled to a Leica EZ 2.1.5 camera, and wound width was measured by image analysis with ImageJ software (https://imagej.nih.gov/ij/). Cell migration was expressed as the percentage of wound closure, calculated with the following formula:

Wound closure $(\%)=100 \times(($ wound width at $0 \mathrm{~h})-($ wound width at $48 \mathrm{~h})) /($ wound width at $0 \mathrm{~h})$.

\subsection{Statistical Analysis}

The statistical analysis used in this study was based on one-way analysis of variance (ANOVA) and Bonferroni post-hoc test for multiple pairwise mean comparisons. The statistically significant was considered when $\mathrm{p}<0.01$. Data were showed as mean \pm S.D.

Author Contributions: Conceptualization, L.C., B.B.; methodology and investigation, M.B., A.S., M.D., D.B., D.T.; writing—original draft preparation, B.B., L.C., A.S.; writing—review and editing, B.B.; supervision, L.C.

Funding: This work was supported by FFABR 2017 grants (ANVUR/MIUR, Italian Ministry of University and Research) (B.B., L.C.). M.B. is recipient of a MIUR PhD scholarship.

Conflicts of Interest: The authors declare no conflict of interest. The funders had no role in the design of the study; in the collection, analyses, or interpretation of data; in the writing of the manuscript, or in the decision to publish the results. 


\section{References}

1. Hossain, M.M. Therapeutic orchids: Traditional uses and recent advances-An overview. Fitoterapia 2011, 82, 102-140. [CrossRef] [PubMed]

2. Mustafa, B.; Hajdari, A.; Pieroni, A.; Pulaj, B.; Koro, X.; Quave, C.L. A cross-cultural comparison of folk plant uses among Albanians, Bosniaks, Gorani and Turks living in south Kosovo. J. Ethnobiol. Ethnomed. 2015, 11, 39. [CrossRef] [PubMed]

3. Chinsamy, M.; Finnie, J.F.; Van Staden, J. Anti-inflammatory, antioxidant, anti-cholinesterase activity and mutagenicity of South African medicinal orchids. S. Afr. J. Bot. 2014, 91, 88-98. [CrossRef]

4. Schuster, R.; Zeindl, L.; Holzer, W.; Khumpirapang, N.; Okonogi, S.; Viernstein, H.; Mueller, M. Eulophia macrobulbon-An orchid with significant anti-inflammatory and antioxidant effect and anticancerogenic potential exerted by its root extract. Phytomedicine 2017, 24, 157-165. [CrossRef]

5. Sut, S.; Maggi, F.; Dall'Acqua, S. Bioactive Secondary Metabolites from Orchids (Orchidaceae). Chem. Biodivers. 2017, 14, e1700172. [CrossRef]

6. Tadokoro, T.; Bonte, F.; Archambault, J.C.; Cauchard, J.H.; Neveu, M.; Ozawa, K.; Noguchi, F.; Ikeda, A.; Nagamatsu, M.; Shinn, S. Whitening efficacy of plant extracts including orchid extracts on Japanese female skin with melasma and lentigo senilis. J. Dermatol. 2010, 37, 522-530. [CrossRef]

7. Hadi, H.; Razali, S.N.; Awadh, A.I. A Comprehensive Review of the Cosmeceutical Benefits of Vanda Species (Orchidaceae). Nat. Prod. Commun. 2015, 10, 1483-1488. [CrossRef]

8. Nguyen, H.C.; Lin, K.H.; Huang, M.Y.; Yang, C.M.; Shih, T.H.; Hsiung, T.C.; Lin, Y.C.; Tsao, F.C. Antioxidant Activities of the Methanol Extracts of Various Parts of Phalaenopsis Orchids with White, Yellow, and Purple Flowers. Not. Bot. Horti Agrobot. 2018, 46, 457-465. [CrossRef]

9. Giri, L.; Belwal, T.; Bahukhandi, A.; Suyal, R.; Bhatt, I.D.; Rawal, R.S.; Nandi, S.K. Oxidative DNA damage protective activity and antioxidant potential of Ashtvarga species growing in the Indian Himalayan Region. Ind. Crops Prod. 2017, 102, 173-179. [CrossRef]

10. Pagani, F. Plant constituents of Orchidaceae. I. Components of Orchis sambucina L., Orchis morio L. Boll. Chim. Farm. 1976, 115, 407-412.

11. Strack, D.; Busch, E.; Klein, E. Anthocyanin patterns in European orchids and their taxonomic and phylogenetic relevance. Phytochemistry 1989, 28, 2127-2139. [CrossRef]

12. Sgarbi, E.; Ranieri, R.; Santunione, G. Effect of Temporary Immersion System on in vitro development of Himantoglossum robertianum (Loisel.) P. Delforge (Orchidaceae). In Proceedings of the $114^{\circ}$ Congresso della Società Botanica Italiana (S.B.I.) — VI International Plant Science Conference, Padova, Italy, 4-7 September 2019; p. 12.

13. Bournérias, M.; Prat, D. Les Orchidées de France, Belgique et Luxembourg, 2nd ed.; Biotope Éditions: Mèze, France, 2005.

14. Gutiérrez, I.R.; Labarga, J.M.M.; Díaz, J.A.; Fernández de Castro, A.G.; Saiz, J.C.M. Expansion of Himantoglossum robertianum (Orchidaceae) in Madrid: A case study on environmental variables and geographical distribution. Mediterr. Bot. 2018, 39, 111-117. [CrossRef]

15. Ertuğ, F. Wild edible plants of the Bodrum area (Mugla, Turkey). Turk. J. Bot. 2004, 28, 161-174.

16. Lentini, F.; Venza, F. Wild food plants of popular use in Sicily. J. Ethnobiol. Ethnomed. 2007, 3, 15. [CrossRef]

17. Ghorbani, A.; Gravendeel, B.; Naghibi, F.; de Boer, H. Wild orchid tuber collection in Iran: A wake-up call for conservation. Biodivers. Conserv. 2014, 23, 2749-2760. [CrossRef]

18. Gallego, E.; Gelabert, A.; Roca, F.; Perales, J.F.; Guardino, X. Identification of volatile organic compounds (VOC) emitted from three European orchid species with different pollination strategies: Two deceptive orchids (Himantoglossum robertianum and Ophrys apifera) and a rewarding orchid (Gymnadenia conopsea). J. Biodivers. Environ. Sci. 2012, 2, 18-29.

19. Smeriglio, A.; Cornara, L.; Denaro, M.; Barreca, D.; Burlando, B.; Xiao, J.; Trombetta, D. Antioxidant and cytoprotective activities of an ancient Mediterranean citrus (Citrus lumia Risso) albedo extract: Microscopic observations and polyphenol characterization. Food Chem. 2019, 279, 347-355. [CrossRef]

20. Thuong, P.T.; Hung, T.M.; Ngoc, T.M.; Ha do, T.; Min, B.S.; Kwack, S.J.; Kang, T.S.; Choi, J.S.; Bae, K. Antioxidant activities of coumarins from Korean medicinal plants and their structure-activity relationships. Phytother. Res. 2010, 24, 101-106. [CrossRef] 
21. Ranzato, E.; Magnelli, V.; Martinotti, S.; Waheed, Z.; Cain, S.M.; Snutch, T.P.; Marchetti, C.; Burlando, B. Epigallocatechin-3-gallate elicits Ca2+ spike in MCF-7 breast cancer cells: Essential role of Cav3.2 channels. Cell Calcium 2014, 56, 285-295. [CrossRef]

22. Elbling, L.; Weiss, R.M.; Teufelhofer, O.; Uhl, M.; Knasmueller, S.; Schulte-Hermann, R.; Berger, W.; Micksche, M. Green tea extract and (-)-epigallocatechin-3-gallate, the major tea catechin, exert oxidant but lack antioxidant activities. FASEB J. 2005, 19, 807-809. [CrossRef]

23. Thring, T.S.; Hili, P.; Naughton, D.P. Anti-collagenase, anti-elastase and anti-oxidant activities of extracts from 21 plants. BMC Complement. Altern. Med. 2009, 9, 27. [CrossRef] [PubMed]

24. Jenkins, G. Molecular mechanisms of skin ageing. Mech. Ageing Dev. 2002, 123, 801-810. [CrossRef]

25. Sarmah, D.; Kolukunde, S.; Sutradhar, M.; Singh, B.K.; Mandal, T.; Mandal, N. A Review on: In Vitro Cloning of Orchids. Int. J. Curr. Microbiol. Appl. Sci. 2017, 6, 1909-1927. [CrossRef]

26. Aybeke, M. Embryo and protoplast isolation from Barlia robertiana seeds (Orchidaceae). Am. J. Plant Sci. 2013, 4, 1. [CrossRef]

27. Calevo, J.; Giovannini, A.; Cornara, L.; Peccenini, S. Asymbiotic seed germination of hand-pollinated terrestrial orchids. Acta Hortic. 2017, 1155, 415-418. [CrossRef]

28. Chieco, C.; Rotondi, A.; Morrone, L.; Rapparini, F.; Baraldi, R. An ethanol-based fixation method for anatomical and micro-morphological characterization of leaves of various tree species. Biotech. Histochem. 2013, 88, 109-119. [CrossRef]

29. Trombetta, D.; Smeriglio, A.; Marcoccia, D.; Giofre, S.V.; Toscano, G.; Mazzotti, F.; Giovanazzi, A.; Lorenzetti, S. Analytical Evaluation and Antioxidant Properties of Some Secondary Metabolites in Northern Italian Monoand Multi-Varietal Extra Virgin Olive Oils (EVOOs) from Early and Late Harvested Olives. Int. J. Mol. Sci. 2017, 18, 797. [CrossRef]

30. Monforte, M.T.; Smeriglio, A.; Germano, M.P.; Pergolizzi, S.; Circosta, C.; Galati, E.M. Evaluation of antioxidant, antiinflammatory, and gastroprotective properties of Rubus fruticosus L. fruit juice. Phytother. Res. 2018, 32, 1404-1414. [CrossRef]

31. Rapisarda, P.; Fanella, F.; Maccarone, E. Reliability of analytical methods for determining anthocyanins in blood orange juices. J. Agric. Food Chem. 2000, 48, 2249-2252. [CrossRef]

32. Barreca, D.; Lagana, G.; Leuzzi, U.; Smeriglio, A.; Trombetta, D.; Bellocco, E. Evaluation of the nutraceutical, antioxidant and cytoprotective properties of ripe pistachio (Pistacia vera L., variety Bronte) hulls. Food Chem. 2016, 196, 493-502. [CrossRef]

33. Smeriglio, A.; Denaro, M.; Barreca, D.; Calderaro, A.; Bisignano, C.; Ginestra, G.; Bellocco, E.; Trombetta, D. In Vitro Evaluation of the Antioxidant, Cytoprotective, and Antimicrobial Properties of Essential Oil from Pistacia vera L. Variety Bronte Hull. Int. J. Mol. Sci. 2017, 18, 1212. [CrossRef] [PubMed]

34. Smeriglio, A.; Alloisio, S.; Raimondo, F.M.; Denaro, M.; Xiao, J.; Cornara, L.; Trombetta, D. Essential oil of Citrus lumia Risso: Phytochemical profile, antioxidant properties and activity on the central nervous system. Food Chem. Toxicol. 2018, 119, 407-416. [CrossRef] [PubMed]

35. Burlando, B.; Pastorino, G.; Salis, A.; Damonte, G.; Clericuzio, M.; Cornara, L. The bioactivity of Hedysarum coronarium extracts on skin enzymes and cells correlates with phenolic content. Pharm. Biol. 2017, 55, 1984-1991. [CrossRef] [PubMed]

36. Muniandy, K.; Gothai, S.; Tan, W.S.; Kumar, S.S.; Mohd Esa, N.; Chandramohan, G.; Al-Numair, K.S.; Arulselvan, P. In Vitro Wound Healing Potential of Stem Extract of Alternanthera sessilis. Evid. Based Complement. Altern. Med. 2018, 2018, 3142073. [CrossRef]

(C) 2019 by the authors. Licensee MDPI, Basel, Switzerland. This article is an open access article distributed under the terms and conditions of the Creative Commons Attribution (CC BY) license (http://creativecommons.org/licenses/by/4.0/). 